\title{
Chronic Disease Multimorbidity Among the Canadian Population: Prevalence and Associated Lifestyle Factors
}

\author{
Nigatu Regassa Geda ( $\square$ negyon@yahoo.com ) \\ Addis Ababa University \\ Bonnie Janzen \\ Saskatchewan Ministry of the Economy \\ Punam Pahwa \\ University of Saskatchewan
}

\section{Research}

Keywords: Chronic disease, morbidity, multimorbidity, lifestyle factors, Canada

Posted Date: July 9th, 2020

DOI: https://doi.org/10.21203/rs.3.rs-39391/v1

License: @) (i) This work is licensed under a Creative Commons Attribution 4.0 International License. Read Full License 


\section{Abstract}

Background and Rationale With the increasing prevalence of most chronic diseases, multimorbidity is becoming an important public health concern in the Canadian population. The purpose of this study was to estimate the prevalence of multimorbidity in the general population based on 14 major chronic diseases and examine associations with lifestyle/behavioral factors.

Methods: The data source was the 2015-2016 Canadian Community Health Survey (CCHS). The CCHS is a cross sectional, complex multistage survey based on information collected from 109,659 participants aged 12+, covering all provinces and territories. Multimorbidity was measured by counting the co-occurrence of two or more chronic diseases within a person. Multiple logistic regression was the primary analysis.

Results: The prevalence of multimorbidity was $33 \%$. Adjusting for sociodemographic variables, there was an increased odds of multimorbidity for those having a sedentary lifestyle $(\mathrm{OR}=1.06 ; \mathrm{Cl}: 1.01-1.11)$ and being obese $(\mathrm{OR}=1.37 ; \mathrm{Cl}: 1.32-1.43)$ or overweight $(\mathrm{OR}=2.65 ; \mathrm{Cl}: 2.54-2.76)$. There were also significant interaction effects on multimorbidity,between sex and smoking, and immigration status and alcohol intake..

Conclusion and Implications: Given the high prevalence of multimorbidity among the general Canadian population, policy makers and service providers should give more attention to the behavioral/lifestyle factors which significantly predicted multimorbidity. Policy and program efforts that promote a healthy lifestyle should be a priority.

\section{Background}

There has been a rapid rise in the prevalence of people living with multiple chronic health problems (ie., multimorbidity)(1-4), including Canada(5,6). Although there is little consensus on how multimorbidity is conceptualized(7), most recent studies have defined the term as the co-occurrence of two or more (chronic) diseases within a person(8). Multimorbidity is associated with significant reductions in functional status and quality of life $(9,10)$.

The prevalence of multimorbidity varies according to the definition used $(2,11)$. In Western countries, the prevalence of multimorbidity has ranged between $20 \%$ and $30 \%$ when the whole population was considered, and between $55 \%$ and $98 \%$ when only older persons were included(12).Multimorbidity prevalence estimateswithin Canada vary from $4 \%$ to over $90 \%$ due to dissimilar study designs and definitions of multimorbidity(6,13-16).For example, a recent study(5)using administrative health data from seven provinces and three territories, estimated a prevalence of $26.5 \%$ based on five conditions (cardiovascular disease, respiratory diseases, mental illness, hypertension, diabetes). Nicholson(2016) reported a prevalence of $42.6 \%$ for the national population aged 18 years and over based on electronic medical record data(17). In another study, Roberts et al (2015) estimated the national prevalence of $12.9 \%$ for two or more chronic diseases for all age groups based on data from the Canadian Community Health Survey(6).

Previous studies around the world have examined the key predictors of multimorbidity. Most of these studies have focused on sociodemographic factors and suggest an increased prevalence of multimorbidity with increasing age $(6,16)$, lower income $(18,19)$,lower income $(20,21)$, and lesseducationa(18,22,23). The few studies which have examined associations between lifestyle factors and multimorbidity suggest that the likelihood of multimorbidity increases with a more sedentary lifestyle ((24,25), obesity(26), and loweralcohol intake(27-29). Most Canadian studies have reported mixed results regarding the socioeconomic and demographic risk factors for multimorbidity $(6,7,14-16)$, with relatively little attention paid to lifestyle factors(16).

Despite the increasing prevalence of multimorbidity over time in Canada, little attention has been given to this issue in the health care system and research is scarce. Only a few population-based studies have been conducted in Canada and of those, have focused on a limited number of chronic diseases $(5,6)$ or potential correlates of multimorbidity $(14)$, and/or investigated only demographic or geographic subpopulations $(14,15,30)$. The present study addresses these limitations by including a more comprehensive list of chronic conditions, all ages and Canadian provinces/ territories, and a more complete list of potential correlates of multimorbidity.

Drawing from the existing literature, we hypothesized that the prevalence of multimorbidity would be significantly higher among those who engage in riskierhealth behaviors (such as smoking, taking alcohol frequently, a sedentary lifestyle, and having higher BMI).

\section{Data Sources And Methodlogy}

\section{Data source, study design and study population}

The present study is based on public use data from the 2015-2016 Canadian Community Health Survey (CCHS). The CCHS is a multistage complex cross-sectional survey that collects a wide range of health and sociodemographic information from participants (31). The 2015-2016 CCHS data covered the population 12 years of age and over living in the ten provinces and the three territories and included a total of 109,659 respondents(31). The data collection excluded persons living on reserves and other Aboriginal settlements in the provinces; full-time members 
of the Canadian Forces; the institutionalized population, children aged 12-17 living in foster care, and some remote areas(31). The exclusions represent less than $3 \%$ of the Canadian population aged 12 and over. The detailed description of methods, design, instruments, participants and sampling frame has previously been published by StatisticsCanada:

http://www23.statcan.gc.ca/imdb/p2SV.pl?Function=getSurvey\&SDDS=3226.

\section{Study variables}

The dependent variable, multimorbidity, was defined as having two or more (2+) chronic conditions from a list of fourteen self-reported diseases, diagnosed by a health professional during a reference period of 6 months prior to the survey.Recent Canadian studies(7) have suggested that limiting the conditions to fewer than seven chronic diseases may result in underestimation of the multimorbidity prevalence, and recommend including 12 or more chronic diseases. The 14 diseases were selected for this study based on their severity, potential impact on mortality, and availability of the information in the CCHS data. These were: joint pain, asthma, chronic obstructive pulmonary disease, sleep apnea, scoliosis, fibromyalgia, arthritis?, osteoporosis, high blood pressure, heart disease, stroke, diabetes, cancer and mood disorder (i.e. depression, bipolar, mania, dysthymia). The multimorbidity variable was computed using simple counts of the reported chronic diseases; a dichotomous variable was created, with a codeof " 1 " given if the respondent reported two or more chronic conditions and " 0 " if the respondent reported less than two conditions.

The exposure variables were categorized into two major groups: sociodemographic characteristics (sex/gender, age, marital status livingarrangement, ethnicity,immigration status, work status, education level,and income); and behavioral risk factors (physical activity level, smoking, alcohol intake, and body mass index (BMI)).

Regarding sociodemographics, age was classified into four groups (years): $<24,25-40,41-65$ and $65+$. Ethnicity was grouped as white, aboriginal or visible minority. Marital status included four categories: married, common-law, widowed/divorced/separated and single/never married. Respondents' educational attainment was grouped into three categories: less than secondary school graduation, secondary school graduation/no post-secondary education, and post-secondary certificate diploma/university education. Annual household income consisted of five groups, with $\$ 20,000$ increments beginning with zero.: No income or less than $\$ 20,000, \$ 20,000$ to $\$ 39,999, \$ 40,000$ to $\$ 59,999, \$ 60,000$ to $\$ 79,999$ and $\$ 80,000$ or more. Work status was measured as 'yes/no' for a reference period of 12 prior to the survey date. Work stress is a selfreported variable (i.e respondents were asked if they currently experience work related experience) and was measure as 'yes/no'. The variable 'living arrangement' was used as a proxy for presence/ absence of social support and was categorized as 'living alone or living with family members/others'.

Among the lifestyle variables, smoking status was divided into three categories: daily, occasionally and not at all. Physical activity was classified according to World Health Organization (WHO) recommendations (active, moderately active, mild active, sedentary)(32). BMI was calculated based on self-reported weight and height and categorized into obese (BMI $30.0 \mathrm{~kg} / \mathrm{m}^{2}$ ), overweight (BMI 25.0-29.9 kg/m²) and normal-to-underweight $\left(\mathrm{BMl}<25.0 \mathrm{~kg} / \mathrm{m}^{2}\right)$. Alcohol intake was classified as regular, occasional and never taker during the last 12 months.

\section{Statistical Analysis}

Data cleaning, management and analysis were carried out using STATA version 13 (33). The distribution of multimorbidity across various sociodemographic and lifestyle/behavioral variables were described using frequencies and proportions. The prevalence of multimorbidity was estimated for the entire sample using weighted proportions with $95 \%$ confidence intervals (95\% Cls).

Following descriptive analyses, a series of bivariate logistic regression analyses were conducted. Variables with a $p<0.20$ were selected for the multivariable logistic regression. In total, 14 variables were entered into the multiple logistic regression model. Confounding was determined if the removal of a nonsignificant variable resulted in a $20 \%$ or more change in regression coefficient $(\Delta \beta \geq 20 \%)$ (34). Odds ratios with $95 \%$ confidence intervals were calculated for each factor in logistic regression model. Multicollinearity among the explanatory variables was checked using the Variance Inflation Factor (VIF) and removed those with VIF greater than 2.5. Two-way interactionswereassesed by entering the product of two hypothesized variables. The final multivariablemodel contained only statistically significant variables.

A sampling weight variable computed by Statistics Canada was used in all analyses to ensure that the final estimates were representative of the Canadian population (31). As CCHS employed cross sectional design, stratification and clustering effects were accounted for by computing robust standard errors of regression coefficients using Tylor linearization techniques.

\section{Results}

Table 1 displays study participant characteristics (weighted). Overall, nearly one-half of the participants were male, and the vast majority were Caucasian. The largest proportionof participants were age $41-65$ years (40.3\%), followed by those in the $25-40$ year age group (23.8\%). Over 
half of the respondents were marriedor cohabitating (58\%) and 60\%reported a post-secondary education. Nonimmigrants made up $75 \%$ of the total participants. Nearly one-half of the participants had an average annual income of $\$ 80,000$ or more, whilea very small proportion (7.3\%) reported having no income or earned less than $\$ 20,000$.

Three-quarters of participants were employed and $8 \%$ reported experiencing work-relatedstress. In terms of living arrangement, $14 \%$ of the participants reported that they lived alone. Thirty-nine percentof respondents reported being physically active and $18 \%$ reported being sedentary. Just over one-half of respondentswere overweightor obese, $12 \%$ were daily smokers and $60 \%$ were regular drinkers (see Table 1 ).

Table 1 Percentage distribution of participants' characteristics, CCHS 2015-16, Canada. 


\begin{tabular}{|c|c|c|}
\hline Sociodemographic characteristics & Weighted \% & Missing (\%) \\
\hline Sex & & 0.0 \\
\hline Male & 49.34 & \\
\hline Female & 50.66 & \\
\hline Ethnicity & & 7.6 \\
\hline White & 80.55 & \\
\hline Aboriginal & 16.36 & \\
\hline Visible minority & 3.09 & \\
\hline Age & & 0.0 \\
\hline$<24$ & 17.53 & \\
\hline $25-40$ & 23.80 & \\
\hline $41-65$ & 40.34 & \\
\hline $65+$ & 18.34 & \\
\hline Marital status & & 0.3 \\
\hline Married & 46.42 & \\
\hline Common-law & 11.36 & \\
\hline Widowed/divorced/separated & 12.16 & \\
\hline Single & 30.06 & \\
\hline Educational level & & 1.4 \\
\hline Less than secondary school graduation & 18.48 & \\
\hline Secondary school graduation, no post-sec education & 21.82 & \\
\hline Post-secondary certificate diploma or university & 59.71 & \\
\hline Immigration Status & & 3.8 \\
\hline Landed immigrant / non-permanent & 25.31 & \\
\hline Non-immigrant (Canadian born) & 74.69 & \\
\hline Living arrangement & & 0.5 \\
\hline Living alone & 14.41 & \\
\hline Living with others & 85.02 & \\
\hline Working status -12 months & & 11.2 \\
\hline Yes & 75.71 & \\
\hline No & 24.29 & \\
\hline Household income & & 0.1 \\
\hline No income or less than $\$ 20,000$ & 7.34 & \\
\hline$\$ 20,000$ to $\$ 39,999$ & 15.16 & \\
\hline$\$ 40,000$ to $\$ 59,999$ & 15.05 & \\
\hline$\$ 60,000$ to $\$ 79,999$ & 14.19 & \\
\hline$\$ 80,000$ or more & 48.26 & \\
\hline
\end{tabular}

Page 5/16 


\begin{tabular}{|c|c|c|}
\hline Physical activity level & & 10.0 \\
\hline Active & 38.5 & \\
\hline Moderately active & 15.0 & \\
\hline Somewhat active & 18.7 & \\
\hline Sedentary & 17.9 & \\
\hline Body Mass Index/ BMI & & 13.4 \\
\hline Underweight or normal & 32.8 & \\
\hline Overweight & 31.0 & \\
\hline Obese - Class I, II, III & 22.8 & \\
\hline Smoking status & & 0.1 \\
\hline Daily & 12.3 & \\
\hline Occasionally & 5.0 & \\
\hline Not at all & 82.7 & \\
\hline Alcohol intake & & 0.5 \\
\hline Regular drinker & 60.1 & \\
\hline Occasional drinker & 16.0 & \\
\hline Did not drink in the last 12 months & 23.4 & \\
\hline
\end{tabular}

Note. *Percentages weighted to the Canadian population.

The overall prevalence of multimorbidity was 33.3\%..As shown in Table 2, the most common two chronic disease combination was joint pain and arthritis (16\%) followed by joint pain and high blood pressure (10\%).

Table 2 Prevalence of the most common two chronic conditions reported, CCHS 2015-16, Canada.

\begin{tabular}{|ll|}
\hline & Weighted \% \\
\hline Joint pain and arthritis & 15.9 \\
\hline Joint pain and high blood pressure & 10.1 \\
\hline Joint pain and mood disorder & 5.1 \\
\hline Joint pain and diabetes & 4.1 \\
\hline Diabetes and high blood pressure & 3.8 \\
\hline
\end{tabular}

Table 3 presents the proportion of respondents with multimorbidity according to sociodemogaphic and lifestyle variables, in addition to unadjusted odds ratios (with $95 \% \mathrm{Cls}$ ). All study variables were significantly associated with multimorbidity. Females were more likely to experience multimorbidity compared to males (36.4\% vs $30.1 \%$ ), and those who reported themselves as 'white' were more likely to have multimorbidity (37\%) compared to Aboriginal people (27\%) and visible minority people (16\%).

The prevalence of multimorbidity increased with advancing age, ranging from $9.4 \%$ for the youngest age group to $66.4 \%$ for the oldest age group. Those who were never married or in a common law relationship had significantly lower prevalences of multimorbidity compared to those married; conversely, those divorced/widowed/separated had a significantly higher prevalence compared to those married (56.5\% vs $37.7 \%)$. Compared to the prevalence of multimorbidity among those who did not graduate high school (35\%), high school graduates had a significantly higher prevalence (36\%), whereas those with a post-secondary degree, significantly lower (32\%). Nonimmigrants were more likely to experience multimorbidity (35\%) compared to immigrants (29\%). The prevalence of multimorbidity decreased with increasing income, from a high of $44 \%$ in the lowest income category, to a low of $27 \%$ in the highest income category. With regards to lifestyle factors, multimorbidity increased as physical activity decreased, from active (30\%) to sedentary (47\%). Multimorbidity was less common in those who smoked 
occasionally $(28 \%)$ or not at all (32\%), compared to daily smokers (41\%). Participants with normal/underweight BMls had a significantly lower likelihood of multimorbidity (26\%) compared to those overweight (34\%) orobese (49\%). Finally, the prevalence of multimorbidity was significantly lower for regular alcohol users (32\%) compared to occasional (38\%) or never users (34\%).

Table 3: Unadjusted odds ratios and 95\% confidence intervals for the association of sociodemographic and lifestyle factors with multimorbidity,CCSH, 2015-2016, Canada. 


\begin{tabular}{|c|c|c|c|c|}
\hline & \multicolumn{2}{|c|}{ Multimorbidity } & \multirow[b]{2}{*}{ Missing(\%) } & \multirow[t]{2}{*}{ OR $_{\text {unadj }}(95 \% \mathrm{Cl})$} \\
\hline & Yes (\%) & No (\%) & & \\
\hline \multicolumn{5}{|l|}{ Sociodemographic Characteristics } \\
\hline Sex & & & 0.0 & \\
\hline Male & 30.13 & 69.87 & & 1 \\
\hline Female & 36.41 & 63.59 & & $1.33(1.27-1.38) \star$ \\
\hline Ethnicity & & & 7.6 & \\
\hline White & 36.71 & 63.29 & & 1 \\
\hline Aboriginal & 26.80 & 73.20 & & $0.59(0.57-0.61)^{*}$ \\
\hline Visible minority & 15.69 & 84.31 & & $0.37(0.34-0.40)^{\star}$ \\
\hline Age & & & 0.0 & \\
\hline$<24$ & 9.43 & 90.57 & & 1 \\
\hline $25-40$ & 15.25 & 84.75 & & $1.73(1.56-1.92)^{\star}$ \\
\hline $41-65$ & 39.30 & 60.70 & & $6.22(5.67-6.82)^{\star}$ \\
\hline $65+$ & 66.39 & 33.61 & & $18.97(17.26-20.87)^{\star}$ \\
\hline Marital status & & & 0.3 & \\
\hline Married & 37.76 & 62.24 & & 1 \\
\hline Common-law & 29.07 & 70.93 & & $0.68(0.63-0.72)^{\star}$ \\
\hline Widowed/Divorced/Separated & 56.48 & 43.52 & & $2.14(2.01-2.27)^{\star}$ \\
\hline Single & 18.73 & 81.27 & & $0.38(0.36-0.40)^{\star}$ \\
\hline Educational level & & & 1.4 & \\
\hline Less than secondary school graduation & 34.48 & 65.52 & & 1 \\
\hline Secondary school graduation & 36.03 & 63.97 & & $1.07(1.01-1.14)^{\star}$ \\
\hline Post-secondary certificate diploma/university & 31.75 & 68.25 & & $0.88(0.84-0.93) \star$ \\
\hline Immigration Status & & & 3.8 & \\
\hline Landed immigrant & 28.95 & 71.05 & & 1 \\
\hline Non-immigrant (Canadian born) & 34.83 & 65.17 & & $1.31(1.24-1.39)^{\star}$ \\
\hline Working status -12 months & & & 11.2 & \\
\hline Yes & 26.00 & 74.00 & & 1 \\
\hline No & 48.95 & 51.05 & & $2.73(2.59-2.87) \star$ \\
\hline Living arrangement & & & 0.6 & \\
\hline Living with family members and others & 48.1 & 51.9 & & 1 \\
\hline Living alone & 30.8 & 69.2 & & $0.47(0.46-0.48)^{\star}$ \\
\hline Household income & & & 0.1 & \\
\hline No income or less than $\$ 20,000$ & 44.11 & 55.89 & & 1 \\
\hline$\$ 20,000$ to $\$ 39,999$ & 42.74 & 57.26 & & 0.95(0.87-1.03) \\
\hline$\$ 40,000$ to $\$ 59,999$ & 38.14 & 61.86 & & $0.78(0.72-0.85)^{\star}$ \\
\hline$\$ 60,000$ to $\$ 79,999$ & 32.69 & 67.31 & & $0.62(0.56-0.67) \star$ \\
\hline$\$ 80,000$ or more & 27.39 & 72.61 & & $0.48(0.44-0.52)^{\star}$ \\
\hline
\end{tabular}




\begin{tabular}{|c|c|c|c|c|}
\hline \multicolumn{5}{|l|}{ Physical activity } \\
\hline Active & 30.36 & 69.64 & 10.0 & 1 \\
\hline Moderately active & 32.93 & 67.07 & & $1.12(1.05-1.20)^{\star}$ \\
\hline Mild active & 35.90 & 64.10 & & $1.28(1.21-1.36)^{\star}$ \\
\hline Sedentary & 46.85 & 53.15 & & $2.02(1.90-2.14)^{\star}$ \\
\hline Smoking & & & 0.1 & \\
\hline Daily & 41.42 & 58.58 & & 1 \\
\hline Occasionally & 27.64 & 72.36 & & $0.54(0.48-0.61)^{\star}$ \\
\hline Not at all & 32.45 & 67.55 & & $0.68(0.64-0.72)^{\star}$ \\
\hline Body mass Index (BMI) & & & 13.4 & \\
\hline Underweight or normal & 25.76 & 74.24 & & 1 \\
\hline Overweight & 34.04 & 65.96 & & $1.48(1.41-1.57)^{\star}$ \\
\hline Obese & 48.72 & 51.28 & & $2.74(2.58-2.90)^{\star}$ \\
\hline Alcohol intake & & & 0.5 & \\
\hline Regular & 31.76 & 68.24 & & 1 \\
\hline Occasional & 37.52 & 62.47 & & $1.29(1.22-1.37)^{\star}$ \\
\hline Not at all & 34.22 & 65.78 & & $1.12(1.06-1.18)^{\star}$ \\
\hline
\end{tabular}

Note. * weighted to the Canadian population.; RC= reference category; The outcome variable is defined as "co-occurrence of two or more (chronic) diseases within a patient. * sig at $<0.05$

The final multivariable logistic regression modelis presented in Table 4 . The odds of multimorbidity decreased by $13 \%$ for aboriginal people (OR=0.87; Cl:0.82-0.91) compared to white people. Compared to those15-24 years of age, the odds of multimorbidity was higher by 1.29 times (Cl:1.18-1.43), 4.29 times (Cl:3.92-4.70) and 7.75 times (Cl: 7.01-8.57) for the 24-40, 41-65, and 65+ years age groups, respectively.

Compared to married respondents, the likelihood of multimorbidity was 1.12 times higher (Cl: $1.10-1.18)$ for those widowed/divorced/separated, and $6 \%$ lower for those with common law partners. Post-secondary graduates were less likely to report multimorbidity ( $\mathrm{OR}=0.93 ; \mathrm{Cl}: 0.88-0.99)$ compared to those who did not graduate high school, and those not employed were 1.67 times more likely to have multimorbidity than their employed counterparts. The chance of experiencing multimorbidity significantly declined as household income increased. The likelihood of multimorbidity was $6 \%$ lower (OR=0.94; $\mathrm{Cl}: 0.89-0.99)$ for respondents who reported living with their family members/others compared to those living alone.

Relative to physically active participants, moderately active participants were .95 times as likely (OR=0.95; Cl:0.91-0.99) and sedentary participants, 1.06 times as likely (OR and 95\%), to report multimorbidity. Compared to those normal/underweight, overweight respondents were 1.37 times $(\mathrm{Cl})$, and obese respondents 2.65 times $(\mathrm{Cl})$, more likely to report multimorbidity.

Table 4: Results of the multiple logistic regression analysis showingthe association between sociodemographic and lifestyle predictors and multimorbidity, CCHS 2015-2016, Canada. 


\begin{tabular}{|c|c|}
\hline Sociodemographic characteristics & $\mathrm{OR}_{\text {adj }}(95 \% \mathrm{Cl}$ \\
\hline \multicolumn{2}{|l|}{ Sex } \\
\hline Male & 1 \\
\hline Female & $1.43(1.32-1.56)$ \\
\hline \multicolumn{2}{|l|}{ Ethnicity } \\
\hline White & 1 \\
\hline Aboriginals & $0.87(0.82-0.91)$ \\
\hline Visible minority & $0.97(0.87-1.08)$ \\
\hline \multicolumn{2}{|l|}{ Age } \\
\hline$<24$ & 1 \\
\hline $25-40$ & $1.29(1.18-1.43)$ \\
\hline $41-65$ & $4.29(3.92-4.70)$ \\
\hline $65+$ & 7.75(7.01-8.57) \\
\hline \multicolumn{2}{|l|}{ Marital status } \\
\hline Married & 1 \\
\hline Common-law & $0.93(0.88-0.99)$ \\
\hline Widowed/Divorced/Separated & $1.12(1.04-1.18)$ \\
\hline Single & $0.94(0.88-0.99)$ \\
\hline \multicolumn{2}{|l|}{ Educational level } \\
\hline Less than secondary school graduation & 1 \\
\hline Secondary school graduation & $0.95(0.89-1.01)$ \\
\hline Post-secondary certificate diploma or unv. & 0.92.(0.87-0.97) \\
\hline \multicolumn{2}{|l|}{ Immigration Status } \\
\hline Landed immigrant & 1 \\
\hline Non-immigrant (Canadian born) & $1.24(1.16-1.32)$ \\
\hline \multicolumn{2}{|l|}{ Working status -12 months } \\
\hline Yes & 1 \\
\hline No & $1.67(1.59-1.74)$ \\
\hline \multicolumn{2}{|l|}{ Living arrangement } \\
\hline Living alone & 1 \\
\hline Living with family members and others & $0.94(0.89-0.99)$ \\
\hline \multicolumn{2}{|l|}{ Household income } \\
\hline No income or less than $\$ 20,000$ & 1 \\
\hline$\$ 20,000$ to $\$ 39,999$ & $0.74(0.68-0.80)$ \\
\hline$\$ 40,000$ to $\$ 59,999$ & $0.69(0.65-0.75)$ \\
\hline$\$ 60,000$ to $\$ 79,999$ & $0.66(0.61-0.71)$ \\
\hline$\$ 80,000$ or more & $0.58(0.54-0.63)$ \\
\hline \multicolumn{2}{|l|}{ Lifestyle variables } \\
\hline Physical activity & \\
\hline
\end{tabular}

Page 10/16 


\begin{tabular}{|ll|}
\hline Active & 1 \\
\hline Moderately active & $\mathbf{0 . 9 5 ( 0 . 9 1 - 0 . 9 9 )}$ \\
\hline Sedentary & $0.99(0.96-1.04)$ \\
\hline Smoking & $\mathbf{1 . 0 6 ( 1 . 0 1 - 1 . 1 1 )}$ \\
\hline Daily & \\
\hline Occasionally & 1 \\
\hline Not at all & $\mathbf{0 . 8 2 ( 0 . 7 3 - 0 . 9 3 )}$ \\
\hline Body mass Index (BMI) & $\mathbf{0 . 7 9 ( 0 . 7 4 - 0 . 8 4 )}$ \\
\hline Underweight or normal & \\
\hline Overweight & 1 \\
\hline Obese & $\mathbf{1 . 3 7 ( 1 . 3 2 - 1 . 4 3 )}$ \\
\hline Alcohol intake & $\mathbf{2 . 6 5 ( 2 . 5 4 - 2 . 7 6 )}$ \\
\hline Regular & \\
\hline Occasional & 1 \\
\hline Not at all & $1.00(0.89-1.13)$ \\
\hline Sex and smoking interaction & $\mathbf{0 . 8 3 ( 0 . 7 5 - 0 . 9 1 )}$ \\
\hline Female and daily smoker & \\
\hline Female and occasional smoker & 1 \\
\hline Female and nonsmoker & $0.95(0.80-1.13)$ \\
\hline Immigration and alcohol intake & $\mathbf{0 . 8 3 ( 0 . 7 6 - 0 . 9 1 )}$ \\
\hline Nonimmigrant and regular alcohol taker & 1 \\
\hline Nonimmigrant and occasional alcohol taker & $\mathbf{1 . 2 3 ( 1 . 0 9 - 1 . 3 9 )}$ \\
\hline Nonimmigrant and non-alcohol taker & $\mathbf{1 . 5 1 ( 1 . 3 6 - 1 . 6 9 )}$ \\
\hline Constant & $.156(.13-0.18)$ \\
\hline
\end{tabular}

Note. $*$ weighted to the Canadian population. $\mathrm{F}(31,41334)=404.54 ;$ Prob $>\mathrm{F}=0.0000$

There were two statistically significant interactions, between sex and smoking, and between immigration status and alcohol intake (Figure). Smoking was more strongly associated with multimorbidity in females than males. The relationship between alcohol intake and multimorbidity was dependent upon immigration status. For Canadians, relative to regular drinkers, the likelihood of multimorbidity increased for occasional drinkers and abstainers. Among immigrants, the likelihood of multimorbidity was similar for regular and occasional drinkers but then decreased for those abstaining.

\section{Discussion}

The prime objective of the study was to estimate the prevalence and risk factors of multimorbidity based on the 2015-2016 CCHS data which included 109,659 participants drawn from all Canadian provinces and territories.

Multimorbidity was experienced by $33 \%$ of the study population. In comparison to other Canadian studies, this prevalence is lower than the $42.6 \%$ reported by Nicholsousing et al (2016)(17) based on a sample of respondents aged 18+. Our estimate is also higher than the prevalence computed by Robert et al (2016)(6), who reported a national prevalence of 2+ chronic conditions, based on five chronic conditions, to be 12.9\%. The difference in estimates across different studies mainly arises from researchers' choice of study groups/populations, the number of chronic conditions considered in the study, or both.The difference may also result from the type of data sources used (such as administrative vs self-reported surveys).For example, the estimated prevalence of multimorbidity by a recent work of Allisonet al (2017)(5) was based on people aged 40+years,considering only five chronic diseases, and using administrative data. The study by Allison and Colleague(5)study has few methodological similarities with ours in terms of target group, data sources used and number of chronic diseases considered; the only 
common trait was the both studies covered all provinces of Canada. In some instances, the definition of multimorbidity itself makes comparisons of prevalence difficult. For instance, while almost all Canadian studies defined multimorbidity as two or more conditions, a recent study by Andrew et al (2019)(16)used an outcome variable of 3 or more chronic conditions and reported a prevalence of multimorbidity in Canada of $14.0 \%$.

The present study assessed the contributionof four lifestyle factors (physical activity level, alcohol intake, smoking and BMI) on multimorbidity.Findings showed a significant inverse association between physical activity level and the occurrence of multimorbidity. This is consistent with recent findings in high-income, middle-income, and low-income countries who reported higher physical activity was associated with multimorbidity (24,25). For instance,Lear etal. (2017)(24)based on a large cohort of 130843 participants from 17 countries (including four low-income countries and seven middle-income countries), reported significant benefits of dose-dependent associations of all forms of physical activity with reduced mortality and cardiovascular disease risks. However, our findingscontrastwith some previous studies(13,35), mainly due to difference in the type of physical activity types considered in the individual studies (i.e., leisure versus general activities) (16).Regarding the observed relationship between activity and multimorbidity, one commonly known pathway for physical activity is that it helps to control excess body weight, and hence, significantly contributes to a reduction in the development of certain chronic diseases such as blood pressure, heart disease, and cancer(16).

The results of this study also showed a significantly higher likelihood of multimorbidity as participants' BMI increased, a result consistent with other findings conducted around the world. For instance, in a recent study by Jovic and collogues (2016)(26), the proportion of participants who reported two or more chronic diseases increased with each BMI category in both sexes, reaching the highest values in obese category III. Obesity is often highlighted because it is simultaneously a disease and a risk factor for other chronic diseases, such as hypertension and diabetes(36). There is a general consensus among researchers and medical practitioners that weight loss or having optimal body weight is usually associated with reductions in the incidence of a number of morbidities, such as diabetes, stroke, heart disease, and others(37-39).This may partly explain why BMI is astrong predictor of multimorbidity in this study.

Recent studies investigating the association between multimorbidity and alcohol intake have reported inverse relationships, suggesting that moderate alcohol use may have protective effects against some chronic diseases, such as dementia, ischemic heart disease, and stroke(2729). In addition, most previous studies have reporteda positive association between smoking and multimorbidity(6). However, most studies have not considered whether health behaviors interact with other variables to impact multimorbidity. Our analyses revealed that the relationship between smoking and multimorbidity was dependent on sex/gender, with smoking have a stronger association with multimorbidity among women than men. Similarly, the relationship between alcohol intake and multimorbidity was dependent on immigrant status; that isAdditional research is needed to clarify why the association between these two health behaviors and multimorbidity is modified by sex/gender and immigrant status.

Other than the lifestyle/ behavioral factors described above, our results also indicated that multimorbidity was associated with several sociodemographic factors, including a a dose response relationship with age. It is well established from other studies that older people are more prone to various commonly known chronic diseases such as heart failure and dementia(6,15,18). One plausible reason for the high multimorbidity in the older age group could be related to numerous age-related changes in the physiological state of the individual, for example, changes in metabolism, immune response, and organ function(40).

The results of this study also showed white participants to have a higherodds of multimorbidity than aboriginal and visible minority participants. This finding agrees with that reported in an American study, in which aboriginals had higher prevalence(23).The finding is inconsistent with someCanadian studies $(6,14,16)$ who comparedthe prevalence of multimorbidity between aboriginal and white population. These studies showed a higher prevalence of multimorbidity among aboriginals compared to whites, adjusting for income and other socioeconomic characteristics. The difference might be due to study coverage and some methodological differences described above.

Widowed/divorced/separated respondents had much higher odds of experiencing multimorbidity compared to those married.While the mechanisms of how marital status influences disease outcomes is not clearly known, some studies attribute the lower multimorbidity among those partnered to improved mental health as a result of social support. $(41,42)$.

We found an inverse, dose response relationship between household income and the prevalence of multimorbidity, indicating that the odds of multimorbidity decreasedas income increased. Previous research conducted in Canada and other parts of the world have reportedinconsistentresults, with some showing, consistent with the present study, a negative association (6,15,35), and others, positive or nonsignificant associations $(20,21)$. Education was also found to be significant predictor of multimorbidity in the present study. Existing evidence suggest that low education level and poor economic condition may combine to increase the likelihood of multimorbidity(22). In other similar studies(18,23), those with higher education had significantly fewer reported diseases. Some authors argue that behind socioeconomic gradients in health are a higher prevalence of risky health behaviors among the poor, such as smoking and alcohol consumption, which are posited as the actual cause of socioeconomic gradients in health(16). However, a behavioral explanation is unlikely in this study, as

Page 12/16 
associations between income and education remained, even after controlling for various health behaviors. The mechanisms by which SES affects multimorbidity likely involves multiple interacting material, behavioral, and psychosocial factorsoccurring throughout the life course(43). In terms of education, people with higher levels of education may better understand and adhere to the prevention and/or treatment of disease, while those with lower education levels may experience more problems related to self-management on a daily basis (41,44).

\section{Strength And Limitations}

Since the study was based on a representative sample of respondents from all provinces, the findings can be generalized to the Canadian population. The results will contribute to to the limited available literature in the field and serve as a reference points for future researchers and policy makers. The findings may also be useful for national level planning, targeting and monitoring and evaluating health outcomes, especially for the most common chronic diseases. However, this study is not without limitations. First, due to its cross-sectional nature, it is difficult to draw temporal relationship between the various exposures and outcome of interest. Second, the chronic health conditions reported in the present study may differwidely in terms of severity which may somehow bias our outcome variable, as it was constructed from a mere count of self-reported chronic morbidities. The self-report nature of multimorbidity might also impact the accuracy of the measurement of the outcome due to possible inaccuracy and omission of information by participants. Comparison of findings with other studies was also difficult due to varied measures of lifestyle exposure variables (such as alcohol intake and physical activity).

\section{Conclusion And Policy Implications}

Given the unacceptable high prevalence of multimorbidity among the general population, these findings suggest that policy makers and service providers should give more attention to the lifestyle factors (i.e., the proximate determinants) which impact the health outcome among a significant proportion of the Canadian population (33.3\%). Policy and program efforts that promote health lifestyle (healthy eating, physical activity, management of body weight, intake of alcohol in moderation and avoid smoking) should be a priority concern. Raising awareness among stakeholders, promoting comprehensive primary care systems that support generalist (i.e doctors who provide services for multiple morbidities) and considering longer consultations for people with multiple conditions could be other strategies to effectively manage multimorbidity in the population.

\section{Abbreviations}

CCHS: Canadian Community and Health Survey

Cl: Confidence Interval

OR: Odds Ratio

SDGs: Sustainable Development Goals

SES: Socio Economic Status

US: United States

WHO: World Health Organization

\section{Declaration}

\section{Ethics approval and consent to participate}

CCHS followed all ethical clearance and procedures for the data collection. Informed consent was obtained from the study participants prior to administration of the questionnaire and taking the anthropometry data .

\section{Consent for publication}

Consent to publish the data was taken from CCHS.

\section{Availability of data and material}

Data are available through permission from CCHS

\section{Funding}

The data owners have no role in financing this publication. 
The authors declare no competing interest, both financial and nonfinancial.

\section{Authors' contributions}

N.R, B.J and P.P involved in the study conception and design. N.R. was responsible for the data analysis. All authors contributed to the discussion, interpreted the findings, critically reviewed/edited the manuscript for intellectual content, and read and approved the final manuscript.

Acknowledgements: The authors would like to gratefully acknowledge Statistics Canada for their kind permission to use the CCHS $2015-2016$ data

\section{References}

1. WHO. Multimorbidity: Technical Series on Safer Primary Care. Geneva; 2016.

2. Violan C, Foguet-Boreu Q, Flores-Mateo G, Salisbury C, Blom J, Freitag M et al. Prevalence, determinants and patterns of multimorbidity in primary care: a systematic review of observational studies. PLoS One. 2014;9(7)::e102149.

3. Sawyer SM, Drew S, Yeo MS, Britto M. Adolescents with a chronic condition: challenges living, challenges treating. Lancet. 2007;369(957):1481-9.

4. Van den Akker M, Buntinx F, Roos S, Knottnerus J. Problems in determining occurrence rates of multimorbidity. J Clin Epidemiol. 2001;54(7):675-9.

5. Allison Feely Lisa M. Lix Kim Reimer. Estimating multimorbidity prevalence with the Canadian Chronic Disease Surveillance System [Internet]. 2017. Available from: https://www.canada.ca/en/public-health/services/reports-publications/health-promotion-chronic-diseaseprevention-canada-research-policy-practice/vol-37-no-7-2017.

6. Roberts KC, Rao DP, Bennett TL, Loukine L, Jayaraman G. Prevalence and patterns of chronic disease multimorbidity and associated determinants in Canada. Heal Promot Chronic Dis Prev Can. 2015;35(6):87-94.

7. Fortin M, Stewart M, Poitras ME et al. A systematic review of prevalence studies on multimorbidity: toward a more uniform methodology. Ann Fam Med. 2012;10(2):142-151.

8. Huntley AL, Johnson R, Purdy S et al. Measures of multimorbidity and morbidity burden for use in primary care and community settings: a systematic review and guide. Ann Fam Med. 2002;10(2):134-141.

9. Le Reste JY, Nabbe P, Manceau B et al. The European General Practice Research Network presents a comprehensive definition of multimorbidity in family medicine and long term care, following a systematic review of relevant literature. J Am Med Dir Assoc. 2013;14(5):319-25.

10. Diederichs C, Berger, K. Bartels D. The measurement of multiple chronic diseases-a systematic review on existing multimorbidity indices. J Gerontol A Biol Sci Med Sci. 2011;66(3):301-311.

11. Arokiasamy P, Uttamacharya U, Jain K. Multi-morbidity, functional limitations, and self-rated health among older adults in India. AGE Open. 2015;5(1):1-5.

12. Marengoni A, Angelman S, Melis R, Mangialasche F, Karp A, Garmen A et al. Aging with multimorbidity: a systematic review of the literature. Ageing Res Rev. 2011;10:430-9.

13. Fortin M, Haggerty J, Almirall J, Bouhali T, Sasseville M, Lemieux M. Lifestyle factors and multimorbidity: a cross sectional study. BMC Public Health. 2014;14(1):686.

14. Kuwornu JP, Lix LM, Shooshtari S. Multimorbidity disease clusters in Aboriginal and non-Aboriginal Caucasian populations in Canada. Chronic Dis Inj Can. 2014;4(34):218-25

15. Agborsangaya CB, Lau D, Lahtinen M, Cooke T, Johnson J. Multimorbidity prevalence and patterns across socioeconomic determinants: $A$ cross-sectional surveyle. BMC Public Health. 2012;12(201).

16. Andrew C. Basham, Mohammad E. Multimorbidity prevalence in Canada: a comparison of Northern Territories with Provinces. Int J Circumpolar Heal. 2019;78(1):1607703.

17. Nicholson K. Multimorbidity in Canada: examining prevalence and patterns using a national electronic medical record database. In: Society for Academic Primary Care 45th annual scientific meeting, July 6-8. Dublin, Ireland; 2016.

18. Marjan Van Den Akker. Determinants of Multimorbidity. The World Book of Family Medicine - European Edition. NY; 2015.

19. Barnett K, Mercer SW, Norbury M, Watt G, Wyke S, Guthrie B. Epidemiology of multimorbidity and implications for health care, research, and medical education: a cross-sectional study. Lancet. 2012;380(9836):37-43.

Page $14 / 16$ 
20. Alaba O, Chola L. The social determinants of multimorbidity in South Africa. Int J Equity Heal [Internet]. 2013;12(63). Available from: https://doi.org/10.1186/1475-9276-12-63.

21. Andrade LH, Bensenor IM, Viana MC, Andreoni S, Wang Y. Clustering of psychiatric and somatic illnesses in the general population: Multimorbidityand socioeconomic correlates. Braz J Med Biol Res. 2010;43(5):483-91.

22. Thanya . Pathirana CAJ. Socioeconomic status and multimorbidity: a systematic review and meta-analysis. Aust NZ J Public Heal. 2018;42:186-94.

23. Quinones A, Liang J, Bennett J, Xu X YW. How does the trajectory of multimorbidity vary across black, white, and Mexican Americans in middle and old age? Journals Gerontol Ser B, Psychol Sci Soc Sci. 2011;66(6):739-49.

24. Lear SA, Hu W, Rangarajan S et al. The effect of physical activity on mortality and cardiovascular disease in 130000 people from 17 highincome, middle-income, and low-income countries: the PURE study. Lancet. 2017;

25. Lee IM, Shiroma EJ, Lobelo F , Puska P, Blair SN, Katzmarzyk P. Effect of physical inactivity on major non-communicable diseases worldwide: an analysis of burden of disease and life expectancy. Lancet. 2012;380:219-29.

26. Jovic D, Marinkovic J, Vukovic D. Association between body mass index and prevalence of multimorbidity: a cross-sectional study. Public Health. 2016;139:103-11.

27. Mohammad Nazmus Sakib1, Shahin Shooshtari, Philip St. John, Verena M. The prevalence of multimorbidity and associations with lifestyle factors among middle-aged Canadians: an analysis of Canadian Longitudinal Study on Aging data. BMC Public Health. 2019;19(243).

28. Peters R, Peters J, Warner J, Beckett N, Bulpitt C. Alcohol, dementia and cognitive decline in the elderly: a systematic review. Aging (Albany NY). 2008;37:505-12.

29. Luchsinger JA, Tang MX, Siddiqui M, Shea S, Mayeux R. Alcohol intake and risk of dementia. . J Am Geriatr Soc. 2004;52:540-6.

30. Koné Pefoyo AJ, Bronskill SE, Gruneir A et al. The increasing burden and complexity of multimorbidity. BMC Public Health. 2015;4(15).

31. Staststics Canada. The 2015-2016 Canadian Community Health Survey (CCHS) [Internet]. 2018. Available from: http://www23.statcan.gc.ca/imdb/p2SV.pl?Function=getSurvey\&SDDS=3226.

32. WHO. Global recommendations on physical activity for health. WHO Library Cataloguing-in-Publication Data [Internet]. [cited 2020 Apr 12]. Available from:

https://apps.who.int/iris/bitstream/handle/10665/44399/9789241599979_eng.pdf;jsessionid=5AF74C76860F1CF420BFD24FE3A90451? sequence $=1$

33. StataCorp. Stata statistical software: release 13. College Station TSL. 2013.

34. Greenland S. Commentary Modeling and Variable Selection in Epidemiologic Analysis. Am J PUblic Heal. 1989;79(3):340-9.

35. Hudon C, Fortin M, Poitras ME, Almirall J. The relationship between literacy and multimorbidity in a primary care setting. BMC Fam Pr. 2012;13(33).

36. Carvalho JNd, de Camargo Cancela M, de Souza D. Lifestyle factors and high body mass index are associated with different multimorbidity clusters in the Brazilian population. PLoS One. 2018;13(11):e0207649.

37. Agrawal S, Agrawal P. Association Between Body Mass index and Prevalence of Multimorbidity in Low-and Middle-income Countries: A Cross-Sectional Study. Int J Med Public Heal. 2016;6(2):73-83.

38. The Look AHEAD Research Group/LARG. Long-term effects of a lifestyle intervention on weight and cardiovascular risk factors in individuals with type 2 diabetes mellitus: four-year results of the Look AHEAD Trial. Arch Intern Med. 2010;170(17):1566-75.

39. DPPRG. Diabetes Prevention Program Research Group. Reduction in the incidence of type 2 diabetes with lifestyle intervention or metformin. Engl J Med. 2002;346(6):393-403.

40. National Academy of Sciences/NAS. The Aging Population in the Twenty-First Century: Statistics for Health Policy [Internet]. 2020. Available from: https://www.ncbi.nlm.nih.gov/books/NBK217739/

41. Bao, X., Xie, Y., Zhang X. . The association between multimorbidity and health-related quality of life: a cross-sectional survey among community middle-aged and elderly residents in southern China. Heal Qual Life Outcomes. 2019;17(107).

42. Han K, Park E, Kim J, Kim SJ, Park S. Is marital status associated with quality of life? Heal Qual Life Out. 2014;12(109).

43. Skalická V, Van Lenthe F, Bambra C, Krokstad S, Mackenbach J. Material, psychosocial, behavioural and biomedical factors in the explanation of relative socio-economic inequalities in mortality: evidence from the HUNT study. Int J Epidemiol. 2009;38(5):1272-84.

44. Smith J. Diabetes and the rise of the SES health gradien:Nber Working Papers. 2007.

\section{Figures}



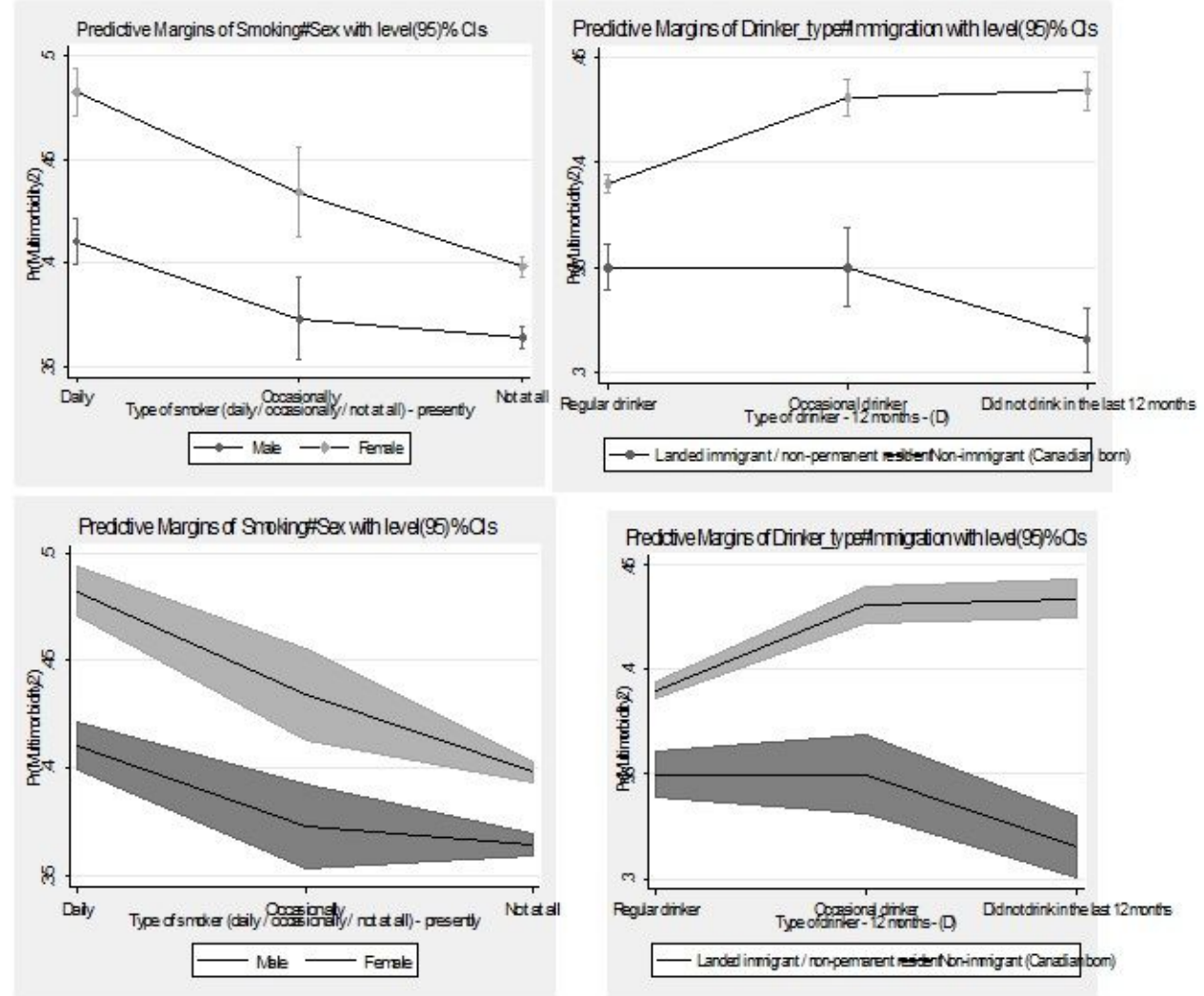

$\rightarrow-$ Larded immigant/non-pernanent nesiber Non-immigant (Caradia born)

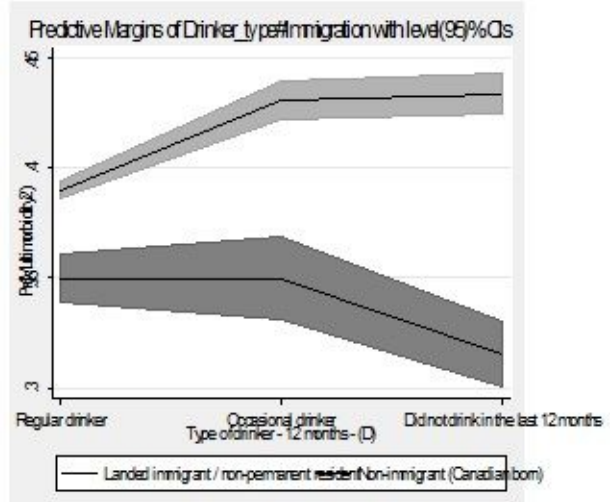

Figure 1

Interaction plots for sex and smoking (left), and immigration and alcohol intake(right),on additive (top) and multiplicative (bottom) scales 